\title{
Effects of accelerators on the cure characteristics and mechanical properties of natural rubber compounds
}

\author{
Q. Ahsan*, N. Mohamad and T.C. Soh \\ Faculty of Manufacturing Engineering, \\ Universiti Teknikal Malaysia Melaka, \\ Durian Tunggal, 76100 Melaka, Malaysia \\ "Email: qumrul@utem.edu.my \\ Phone: +606-3316510, Fax: +606-3316431
}

\begin{abstract}
The effects of different accelerators on the cure characteristics and mechanical properties of sulphur-cured natural rubber (NR)-based compounds are investigated. Three accelerator systems, with mercaptobenzothiazole disulphide (MBTS) as primary accelerator and diphenylguanidine (DPG) and Zn-2-mercaptobenzothiazole (ZMBT) as secondary accelerators, were incorporated into a premixed NR compound referred to an industrially used rubber mat formulation by using the melt mixing method. The cure characteristics, rubber crosslink density and mechanical properties were the focus in the present study. It is observed that the synergistic effect of the MBTS/DPG combination imparts the shortest scorch time, highest cure rate and highest crosslink density compared with the MBTS/ZMBT and MBTS/ZMBT/DPG combinations. Mechanical tests indicate that the tensile strength and modulus of MBTS/DPG are enhanced owing to improved cure activation in initiating sulphuric crosslinking, but the tear strength is decreased compared with the others. This study demonstrates that the MBTS/ZMBT/DPG system is the most effective in enhancing tear strength by $4.5 \%$ compared with MBTS/DPG system, as well as other mechanical properties. Analyses on tear behaviours and scanning electron microscope (SEM) micrographs of the fractured surfaces of tear test samples correspond well with the results of tear strength.
\end{abstract}

Keywords: Accelerators; natural rubber; crosslink; sulphur curing; tear strength.

\section{INTRODUCTION}

A sulphur-cured system is the most commonly used curing method in the rubber industry [1-3]. It provides advantages of lower cost, lower toxicity, better compatibility with other compounding additives and predictable vulcanisation properties [1]. In sulphur curing, two or more accelerators are used to accelerate the cure by providing a synergistic curing effect [4]. An accelerator with a slower cure serves as the primary accelerator, reacting with another faster type that serves as the secondary accelerator. Sometimes, a mixture of up to three accelerators may be used to optimise the rate of cure [5]. Accelerators strongly influence not only the processing safety and the cure characteristics of a compound, but also its final properties $[1,4,6]$. In terms of controlling scorch time, the types of accelerator used are more significant than their level, although an increased level can increase the crosslink density [7]. Thiazole-based accelerators are the most widely used type, among which mercaptobenzothiazole disulphide (MBTS) is the most prominent [8]. Compared with other accelerators, MBTS presents the greatest processing safety, has a satisfactory cure rate and provides rubber compounds with good aging properties [9]. 
Work by Susamma et al. [4] on synergising the secondary accelerator $N$-amidino- $N{ }^{\prime}-$ phenylthiourea (APT) with MBTS and with tetramethylthiuram disulphide (TMTD) found that the APT/MBTS system provides better mechanical properties, which can be attributed to a higher proportion of poly-sulphuric crosslinking. Moreover, [10] showed that a natural rubber (NR)/EPDM blend with added MBTS exhibited a longer cure time, lower crosslink density, lower hardness but highest elongation at break, along with higher tensile and tear strengths, compared with the vulcanizates obtained by using the accelerators $N$-tert-butyl-2-benzothiazole sulphonamide (TBBS) and TMTD.

Diphenylguanidine (DPG) is most frequently used as a secondary accelerator to synergise with thiazole accelerators. As secondary accelerator, DPG in combination with MBTS contributes to a powerful cure activation effect that imparts high modulus, tensile strength, dynamic and aging properties of rubbers [5]. In MBTS acceleration systems, soluble $\mathrm{Zn}^{2+}$ reacts with accelerators-polysulphides $\left(\mathrm{Ac}-\mathrm{S}_{x}-\mathrm{Ac}\right)$ to form complex $\mathrm{Zn}$ polysulphides-accelerators $\left(\mathrm{Ac}-\mathrm{S}_{x}-\mathrm{Zn}-\mathrm{S}_{x}-\mathrm{Ac}\right)$, in the presence of amine molecules to increase the cure rate [11]. However, the MBTS/DPG system that is commonly used in the rubber industry may result in an excessively high cure activation effect. This can lead to a decrease in the cure scorch time, deterioration of the proper heat flow of the compound, and a dramatic increase in crosslink density, which may be undesirable for those rubber compounds that require better scorch safety and mechanical properties. There has been increasing use of Zn-2-mercaptobenzothiazole (ZMBT) in the latex process because of its more rapid effect than MBTS in accelerating cure [7]. However, ZMBT has not been examined thoroughly as a secondary accelerator in dry rubber sulphur-cured systems, especially when synergised with MBTS and DPG. This research therefore focuses on the synergistic effects of three different accelerator combinations, namely MBTS/DPG (MD), MBTS/ZMBT (MZ) and MBTS/ZMBT/DPG (MZD), on the mechanical properties of a non-black NR compound used for the manufacture of rubber mats.

\section{EXPERIMENTAL DETAILS}

\section{Materials}

The detailed information on the NR and accelerators used is presented in Table 1. Other rubber ingredients, including calcium carbonate, white $\mathrm{ZnO}$ activator, stearic acid, polyethylene glycol, phenolic antioxidant, paraffin oil, metal soap, titanium dioxide and sulphur, were the grades customarily used in the rubber industries.

\section{Formulation and Mixing}

Melt compounding was performed according to ASTM D3182 by using a laboratoryscale two-roll mill (Radicon) with a friction ratio of 1.25. The nip of the rollers was adjusted during mixing and the compound was cut and folded using a cutter knife. An NR-based compound (NRAMB) was prepared with the composition shown in Table 2 (in parts per hundred rubber [phr], with reference to an industrially used rubber mat formulation from a rubber products manufacturer, Rubber Leisure Products Sdn. Bhd.). As shown in Table 3, samples of the NRAMB were mixed with the various accelerator combinations (MD, MZ and MZD), with $97.45 \%$ NRAMB and $2.55 \%$ accelerator. The percentages of primary and secondary accelerators were referred to the similar ratio used in the industry. Finally, the compounds were mixed with $3 \mathrm{~g}$ sulphur under controlled mixing parameters. 
Table 1. Information on NR and accelerators.

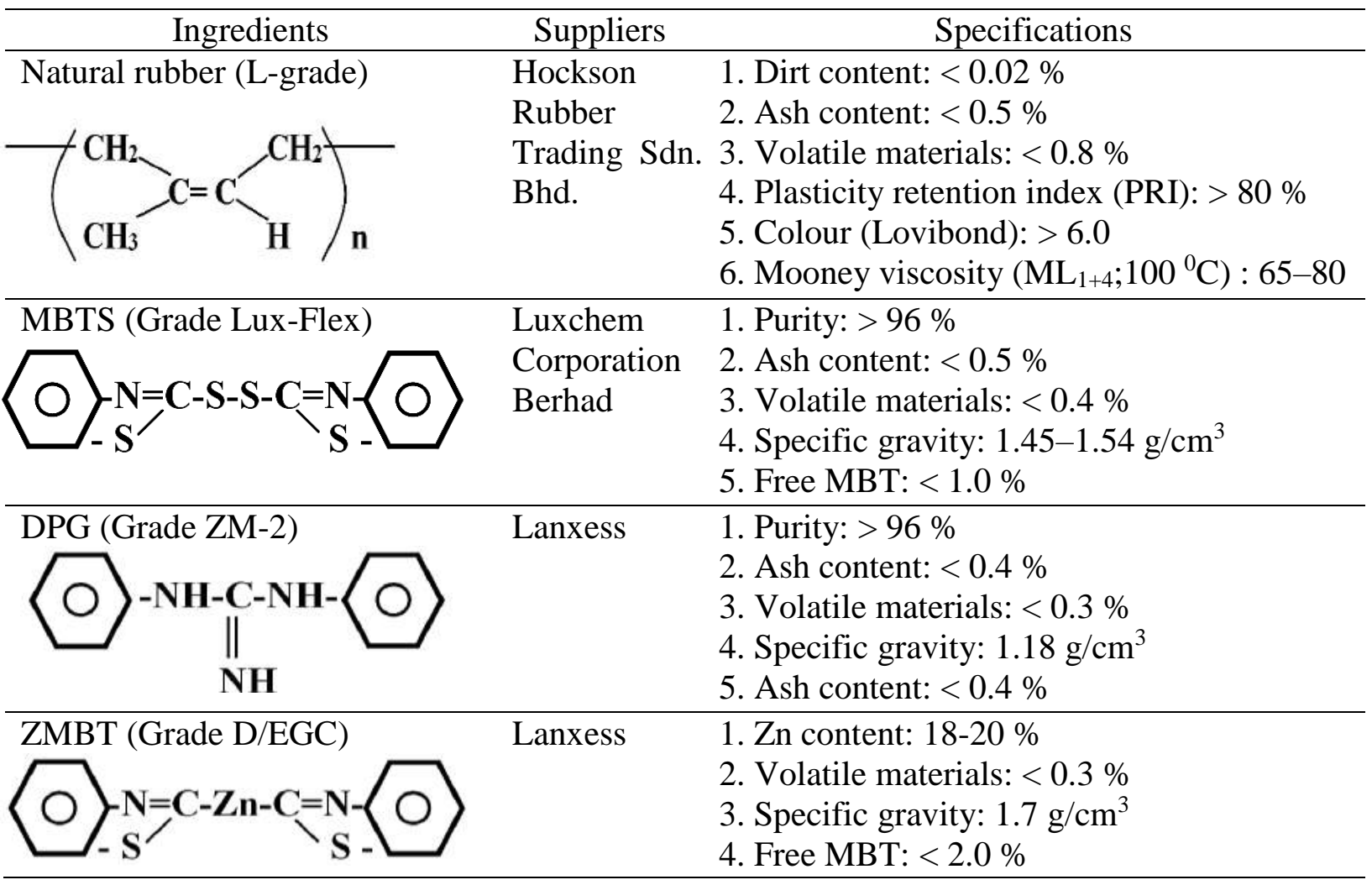

Table 2. Formulation of NR-based compound (NRAMB).

\begin{tabular}{ll}
\hline Ingredients & $\mathrm{phr}^{\mathrm{a}}$ \\
\hline Natural Rubber SMR L & 100.00 \\
Calcium carbonate & 10.00 \\
Phenolic antioxidant & 0.50 \\
Paraffinic oil & 0.50 \\
Zn oxide white & 3.00 \\
Stearic acid & 2.00 \\
Polyethylene glycol & 2.00 \\
Metal soap & 0.50 \\
TiO $_{2}$ & 2.50 \\
\hline Total & 121.00 \\
\hline \multicolumn{2}{c}{${ }^{a}$ parts per hundred rubber }
\end{tabular}

Table 3. Various combinations of accelerators mixed with NRAMB.

\begin{tabular}{|c|c|}
\hline Ingredients & Codes \\
\hline $97.45 \%$ NRAMB + $2.32 \%$ MBTS + $0.23 \%$ DPG & MD \\
\hline $97.45 \%$ NRAMB + $2.32 \% \mathrm{MBTS}+0.23 \%$ ZMBT & $\mathrm{MZ}$ \\
\hline $97.45 \%$ NRAMB $+2.32 \%$ MBTS $+0.115 \%$ ZMBT $+0.115 \%$ & MZD \\
\hline
\end{tabular}




\section{Cure Characteristics of Vulcanizates}

Cure characteristics were tested using an oscillating rotorless rheometer (UR2010 from U-CAN Dynatex Co. Ltd, Taiwan) with upper and lower dies in compliance with ASTM D5289 at a set temperature of $165^{\circ} \mathrm{C}$, a cure time of $240 \mathrm{sec}$. and a pressure of 4.5 $\mathrm{kg} \mathrm{cm}^{-2}$. The compounds were conditioned for $24 \mathrm{~h}$ at ambient temperature $23-27{ }^{\circ} \mathrm{C}$ before the test. The scorch time $\left(T_{2}\right)$, cure rate index (CRI) and rheometry crosslink density ( $\Delta$ torque) were recorded for each compound tested. The cure reaction in terms of CRI is determined from Eq. (1) as follows [12]:

$$
C R I=100 /\left(T_{90}-T_{2}\right)
$$

where $T_{90}$ is the time at $90 \%$ cure and $T_{2}$ is the time for the torque to increase two units above the minimum torque at a given cure temperature, representing the scorch safety of rubber compound.

\section{Testing and Analysis of Compounds}

All compounds were cured by using a 250-tonne hydraulic compression press (M11067, from Dah Tyan Co. Ltd., Taiwan) at $165^{\circ} \mathrm{C}$ according to the optimum cure time $T_{90}$ for producing a vulcanised rubber mat of thickness $0.55 \mathrm{~mm}$. Tensile strength was determined by tensile testing according to ASTM D412 using a Zwick Roell Z005 tensile testing machine. A tear test was performed using trouser-shaped test-pieces, with reference to ASTM D624. Fourier-transform infrared (FTIR) spectroscopy was carried out by using a machine of model Spectrometer 6700. Attenuated total reflectance (ATR) spectroscopy was used to analyse the spectra of the vulcanizates in the range of 400-4000 $\mathrm{cm}^{-1}$. Crosslink density was determined using a solvent penetration method. Specimens of dimensions $30 \mathrm{~mm} \times 20 \mathrm{~mm} \times 0.55 \mathrm{~mm}$ were immersed in $100 \mathrm{ml}$ of toluene (density $0.865 \mathrm{~g} \mathrm{ml}^{-1}$ and boiling point $110{ }^{\circ} \mathrm{C}$ ) for $24 \mathrm{~h}$ at room temperature to allow equilibrium penetration of the solvent into the rubber matrix. The molecular weight of the polymer between crosslinks was determined from the Flory-Rehner equation [13] as shown in Eq. (2) below:

$$
M_{\mathrm{c}}=\frac{{ }_{\mathrm{r}} V_{\mathrm{s}}\left({ }_{\mathrm{r}}^{1 / 3}{ }_{\mathrm{r}} / 2\right)}{\ln \left(1 \mathrm{r}_{\mathrm{r}}\right)+{ }_{\mathrm{r}}+{ }_{\mathrm{r}}^{2}},
$$

where $\rho_{\mathrm{r}}$ is the density of the rubber, $V_{\mathrm{s}}$ is the molar volume of toluene determined at $106.52 \mathrm{~cm}^{3} \mathrm{~mol}^{-1}, \Phi_{\mathrm{r}}$ is the volume fraction of the rubber and $\chi$ is the Huggins polymersolvent interaction parameter fixed at 0.3795 . The crosslink density was then determined from Eq. (3) [13]:

$$
V_{e}=\frac{1}{2 M_{c}}
$$

Tear behaviour was determined by examining the crack tips of tear test samples under an optical microscope (Meiji Techno, EMZ13TR). The tear pattern propagating along the tear path was examined via digital camera images. Scanning electron micrographs of fracture surfaces at crack tips and the centre of the tear paths of samples were obtained using a Zeiss EVO50 scanning electron microscope with an accelerating voltage of $15 \mathrm{kV}$ under a magnification of $1000 \times$. 


\section{RESULTS AND DISCUSSION}

\section{Cure Characteristics}

Results for the cure characteristics are presented in Table 4. Among the three accelerator combinations, MZ shows the longest $T_{2}$ and MD the shortest, with the fastest onset of vulcanisation, while MZD provides a moderate result. It can be inferred that MD initiates fast sulphuric crosslinking with unsaturated rubber backbones to confer the highest CRI and shortest $T_{2}$. In the case of MD, the greater number of amine functional groups in the DPG results in an effective synergistic effect with MBTS, with the formation of accelerator-Zn-polysulphide complexes leading to a faster cure activation effect. Amine groups can effectively activate a faster cure reaction of MBTS [14].

Table 4. Cure characteristics of the three accelerator systems.

\begin{tabular}{llll}
\hline Combinations & MD & MZ & MZD \\
\hline $\mathrm{T}_{2}(\mathrm{sec})$. & 60.33 & 66.67 & 63.67 \\
$\mathrm{~T}_{90}(\mathrm{sec})$. & 95.67 & 108.00 & 100.67 \\
$\left.\mathrm{CRI}^{(m i n} .^{-1}\right)$ & 169.84 & 145.18 & 162.24 \\
$\Delta$ torque $^{(\mathrm{dNm})}$ & 20.44 & 19.39 & 20.17 \\
\hline
\end{tabular}

With regard to MZ, it can be inferred that the combination of MBTS and ZMBT mainly forms cured compounds from the cyclohexyl groups of MBTS associated with soluble $\mathrm{Zn}$ of $\mathrm{ZMBT}$. [15] reported that $\mathrm{Zn}^{2+}$ forms $\mathrm{Zn}$-accelerators-polysulphides complex with the nitrogen atom on the benzothiazole moiety of MBTS, as illustrated in Figure 1.<smiles></smiles>

Figure 1. Formation of MBTS cure acceleration complex in the presence of soluble $\mathrm{Zn}$ [15].

Following this lead, ZMBT is ineffective in providing a secondary acceleration effect on the cure rate, unlike DPG. However, the slower cure activation effect of MD and MZD is beneficial from the perspective of scorch safety. Thus, ZMBT can act as a scorch-safe secondary accelerator, with the longer $T_{2}$ allowing the rubber compound to flow smoothly without scorching before the desired shape is reached in the mould cavity.

\section{FTIR Analysis}

Figure 2 shows the ATR-FTIR spectra. Strong bands in the range of $2744-3015 \mathrm{~cm}^{-1}$ for all samples correspond to the asymmetric and symmetric stretching frequencies of $\mathrm{C}-\mathrm{H}$ groups in NR. A minor increase in the intensity of the region $600-700 \mathrm{~cm}^{-1}$ for MD corresponds to extra stretching of $\mathrm{C}-\mathrm{S}$, which is ascribed to the greater number of sulphuric crosslinks resulting from the better cure acceleration effect of MBTS/DPG. 
Higher intensity of the peak at $1430-1650 \mathrm{~cm}^{-1}$ is observed for MZ over MD because a greater amount of $\mathrm{C}=\mathrm{C}$ stretching is attributed to the more highly unsaturated nature of the polymer backbones of MZ. This further supports the fewer double bonds engaged in the sulphuric cure, which are attributed to the weaker MBTS/ZMBT acceleration system. Minor extra peaks at the region of $1500-1750 \mathrm{~cm}^{-1}[16]$ and higher intensity at 1040 $1090 \mathrm{~cm}^{-1}$ [17] for MD are evidence of $\mathrm{N}-\mathrm{H}$ bending and $\mathrm{C}-\mathrm{N}$ stretching respectively, resulting from the greater number of amine groups in DPG.

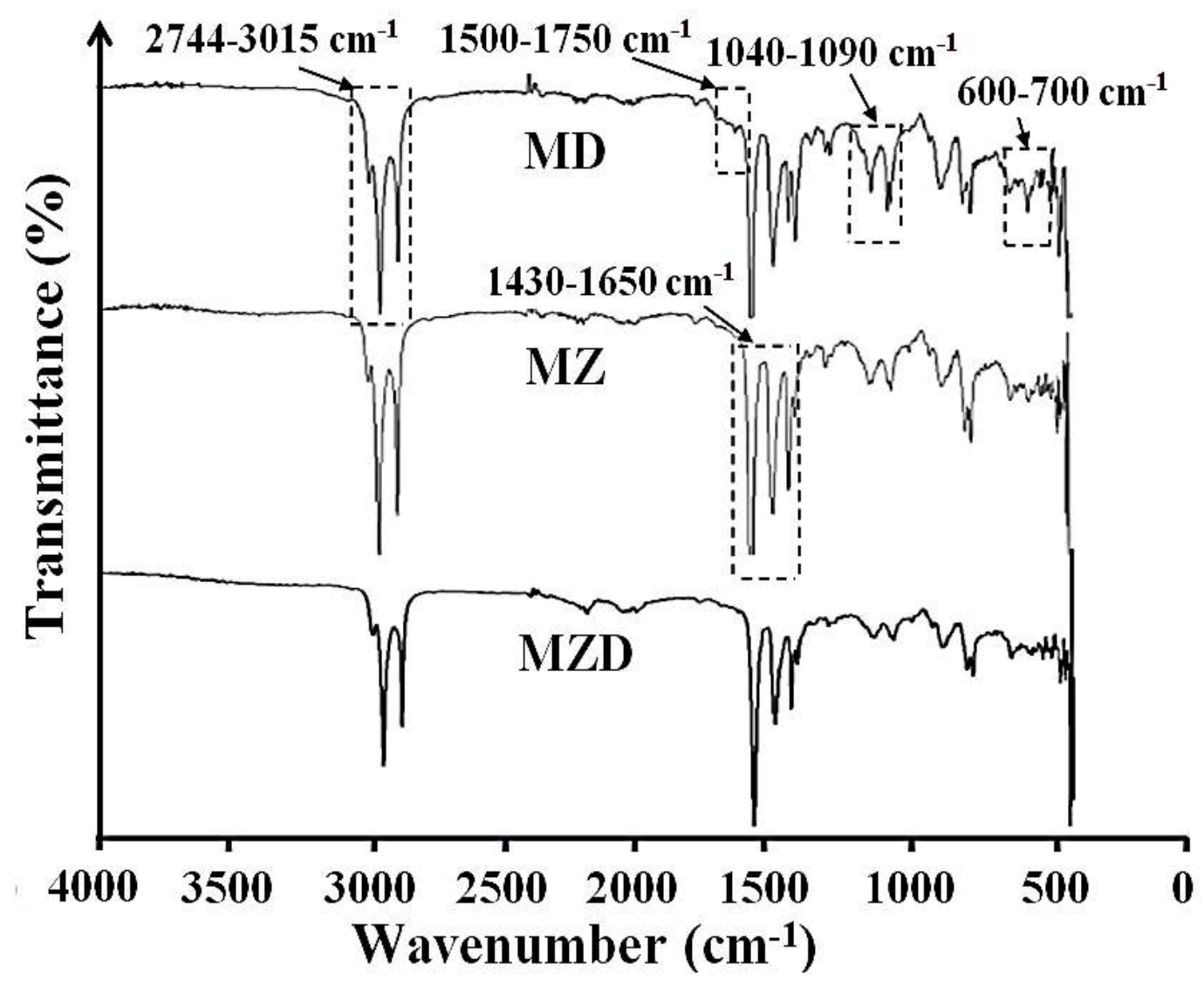

Figure 2. FTIR spectra for MD, MZ and MZD.

\section{Crosslink Density and Mechanical Properties}

Results for the crosslink density obtained from the solvent penetration method are shown in Table 5. The compound with MD has the highest crosslink density of $3.57 \times 10^{-5}$ mol g ${ }^{-1}$. These results are consistent with the preceding results for $\Delta$ torque obtained by rheometry (Table 4). As expected, the compound with MZ has the lowest crosslink density of $3.18 \times 10^{-5} \mathrm{~mol} \mathrm{~g}^{-1}$, while the crosslink density of the compound with MZD $\left(3.46 \times 10^{-5} \mathrm{~mol} \mathrm{~g}^{-1}\right)$ is close to that obtained with MD. Therefore, MZD can be considered as an ideal accelerator system in which to provide both a sufficiently high crosslink density and a longer scorch time than the conventional combination of MBTS and DPG. Table 5 shows that the highest tensile strength and modulus at $300 \%$ elongation (M300\%) are found for the compound with MD. The compound with MZ has the lowest tensile strength and M300\%, while the compound with MZD exhibits values between those for MZ and MZD. The variations in M300\% across the vulcanizates exhibit the same trend as for tensile strength. Figure 3 shows that both tensile strength and M300\% increase in parallel with increasing crosslink density. In particular, the modulus increases 
monotonically with the density of crosslinks formed in the rubber [6, 13]. A few researchers supported the increased trends of tensile strengths of the rubber $[18,19]$ and kenaf-reinforced polyethylene [20] proportionately to the stress modulus. In this context, it is evident that the higher crosslink density imparted by the synergistic curing effect of MBTS and DPG serves more effectively to constrain the mobility of polymer chains and confers greater tensile strength and modulus.

Table 5. Crosslink density and mechanical properties of the three accelerator systems.

\begin{tabular}{llll}
\hline Combinations & MZ & MZD & MD \\
\hline Crosslink density $\left(\mathrm{V}_{\mathrm{e}} \times 10^{-5} \mathrm{~mol} \mathrm{~g}^{-1}\right)$ & $3.18 \pm 0.16$ & $3.46 \pm 0.17$ & $3.57 \pm 0.10$ \\
Modulus at 300\% elongation $(\mathrm{MPa})$ & $1.90 \pm 0.17$ & $1.93 \pm 0.06$ & $2.00 \pm 0.10$ \\
Tensile strength $(\mathrm{MPa})$ & $22.67 \pm 3.33$ & $24.13 \pm 0.75$ & $24.87 \pm 1.21$ \\
Tear strength $(\mathrm{N} / \mathrm{mm})$ & $4.57 \pm 0.15$ & $4.60 \pm 0.10$ & $4.40 \pm 0.10$ \\
\hline
\end{tabular}

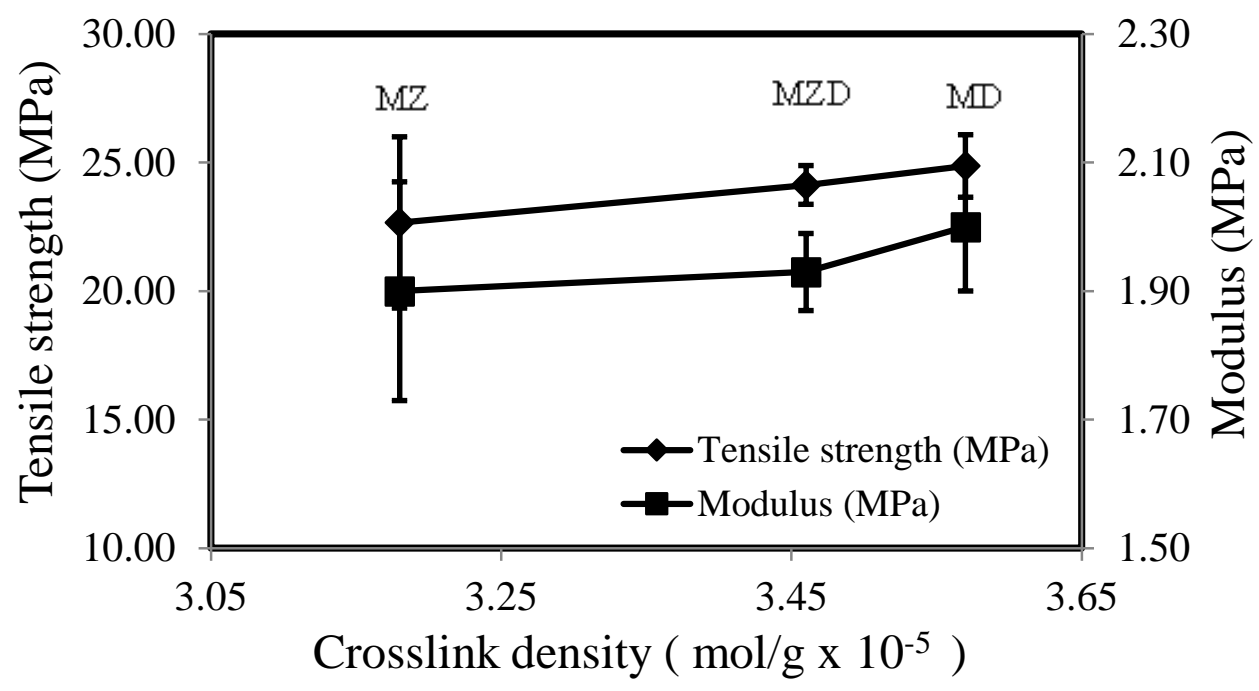

Figure 3. Tensile strength and M300\% against crosslink density.

The relationship between tear strength and crosslink density is depicted in Figure 4. Although the compound with MD attains the highest tensile strength and crosslink density, it exhibits an adversely low value of tear strength, with a reduction of $4.5 \%$ compared with MZD. This can be attributed to the higher crosslink density produced by MD, which constrains the strain along the tear propagation path. As pointed out by Gent [7], the tear strength initially increases as the crosslink level increases, but, after reaching a maximum value, it decreases at excessively high crosslink levels, which restrict chain motions so that the tight network is incapable of dissipating much energy, resulting in relatively easy, brittle fracture at low elongation. This is consistent with the results of [21], which showed that increasing the level of vulcanisation agent and thereby crosslink density initially enhances the mechanical properties, but beyond a certain level further increases have the opposite effect. Alternatively, as compared with the use of MD, it can be inferred that the use of MZ and MZD provide lower crosslink levels that favour tear strength. 


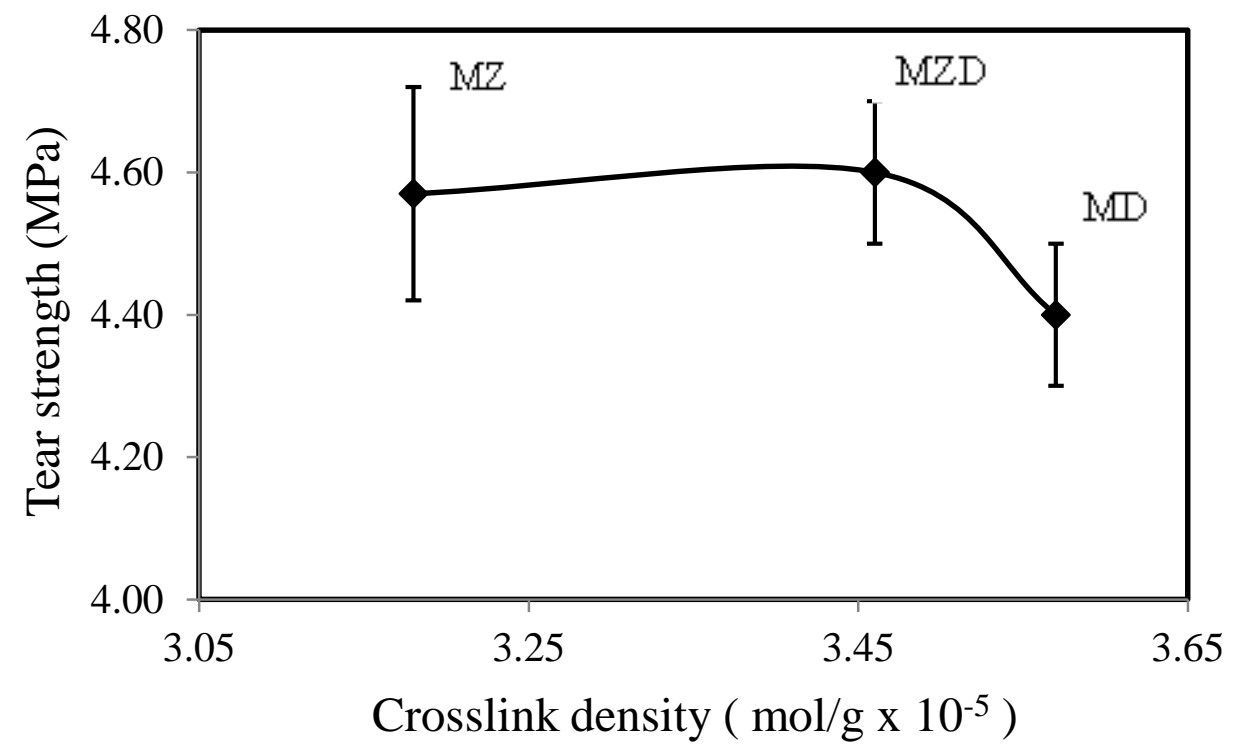

Figure 4. Tear strength against crosslink density.

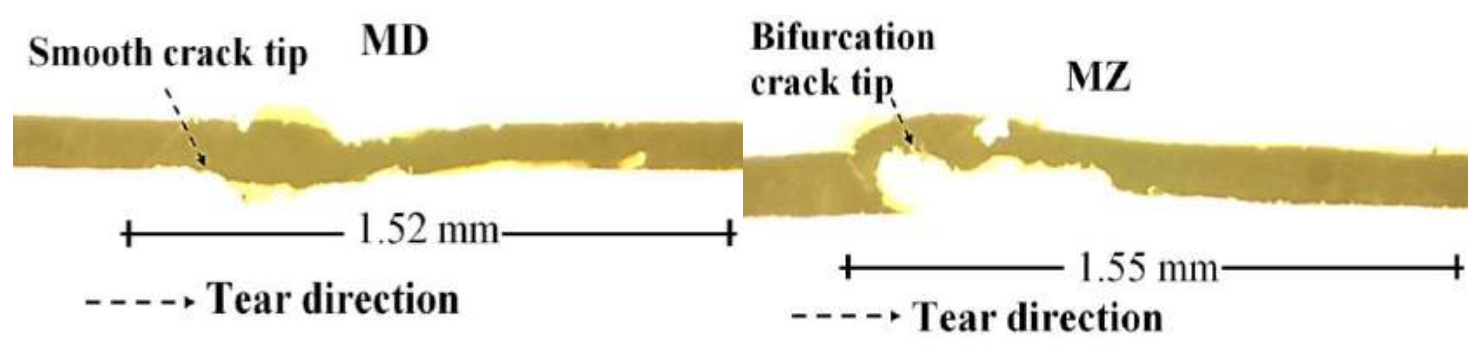

(a)

(b)

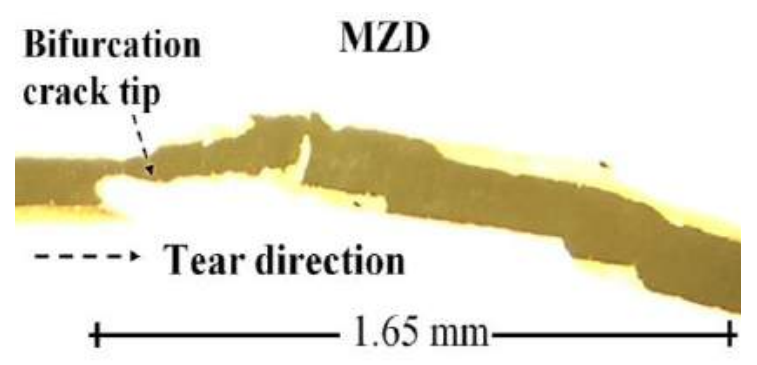

(C)

Figure 5. Optical micrographs of tear profiles at crack tips of (a) MD, (b) MZ and (c) MZD.

\section{Tear Behaviour}

The optical micrographs in Figure 5 shows the tear behaviour of edge-cut tear pieces in the region around the crack tip. A smooth tear pattern is observed for the compound with MD, with few crack bifurcations at the crack tip, whereas in the compounds with $\mathrm{MZ}$ and MZD, the crack tips are blunted and propagate as jagged tear patterns. These tear behaviours are consistent with the higher forces required to initiate tearing in the compounds with MZ and MZD. For the compound with MD, which has the lowest tear strength, fewer and lower peaks and a shorter and smoother tear path are observed, as 
shown in Figure 6. On the contrary, the plots of tear force versus tear path for the compounds with MZ and MZD in Figure 7 and Figure 8, respectively, show higher multiple peaks in the tear patterns, with longer tear paths. The results in Figures 6-8 are consistent with the ways in which the crack patterns are seen to propagate along the tear paths in the images of the tear specimens. They also provide further evidence that the greater energy dissipation and deviations in the crack paths for the compounds with $\mathrm{MZ}$ and MZD confer higher tear strengths. Deviation of the crack path in the crack tip region can effectively eliminate stress concentration and enhance resistance to crack growth [22]. Thus, as a result of the high crosslink density that it produces, MD imparts a greater extent of stress constraint, thus decreasing its effectiveness in releasing strain energy. A high crosslink density slows the kinetics of strain-induced crystallisation, and the resulting tightly constrained macromolecular networks produce a material with lower tear strength [23]. It is evident that the clear differences in crack behaviour observed between the different accelerators are closely related to the preceding results on tear strength. It can also be inferred that the optimal crosslink density conferred by MZD enhances the tear performance of the vulcanizate, in a manner consistent with the tear strength results.

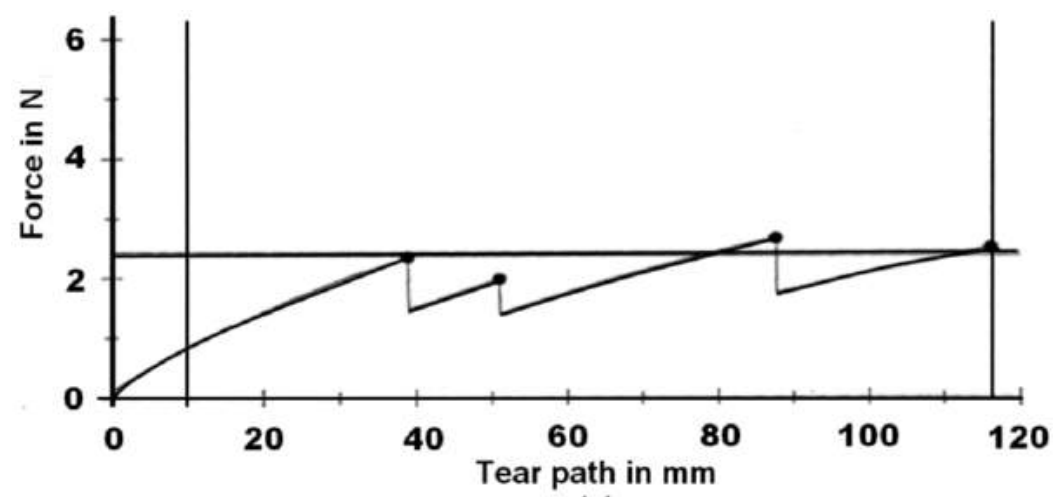

(a)

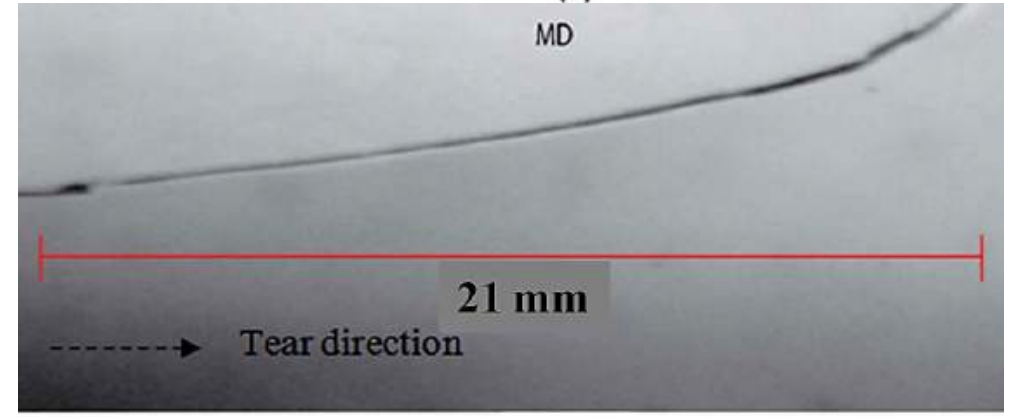

(b)

Figure 6. (a) Tear force vs. tear path diagram and (b) macroscopic tear path of MD.

To obtain better insight into the tear topography, scanning electron micrographs of fracture surfaces at the crack tips and the centres of the tear paths were obtained by secondary electron imaging at a magnification of $1000 \times$, as shown in Figure 9. The presence of a microscopically smooth tear surface with a small ripple-like pattern in the compound with MD is further evidence of a macroscopic crack path with the lowest tear strength value in this material. The fracture surfaces of the compounds with MZ and MZD demonstrate rougher surface profiles with broader deformation bands. A rougher fracture surface with ridges and valleys as well as a greater amount of matrix tearing or a greater number of tearing lines requires a higher energy to fail, which is contributed by better tear 
performance [23, 24]. Thus, the rough tear surfaces of the compounds with MZ and MZD represent more effective crack blunting on tear paths, in contrast to the sharp and straight tear propagation in the compound with MD. These observations are consistent with the differences in tear strength correlated with the crosslink density obtained with the different accelerator systems investigated in the present work.
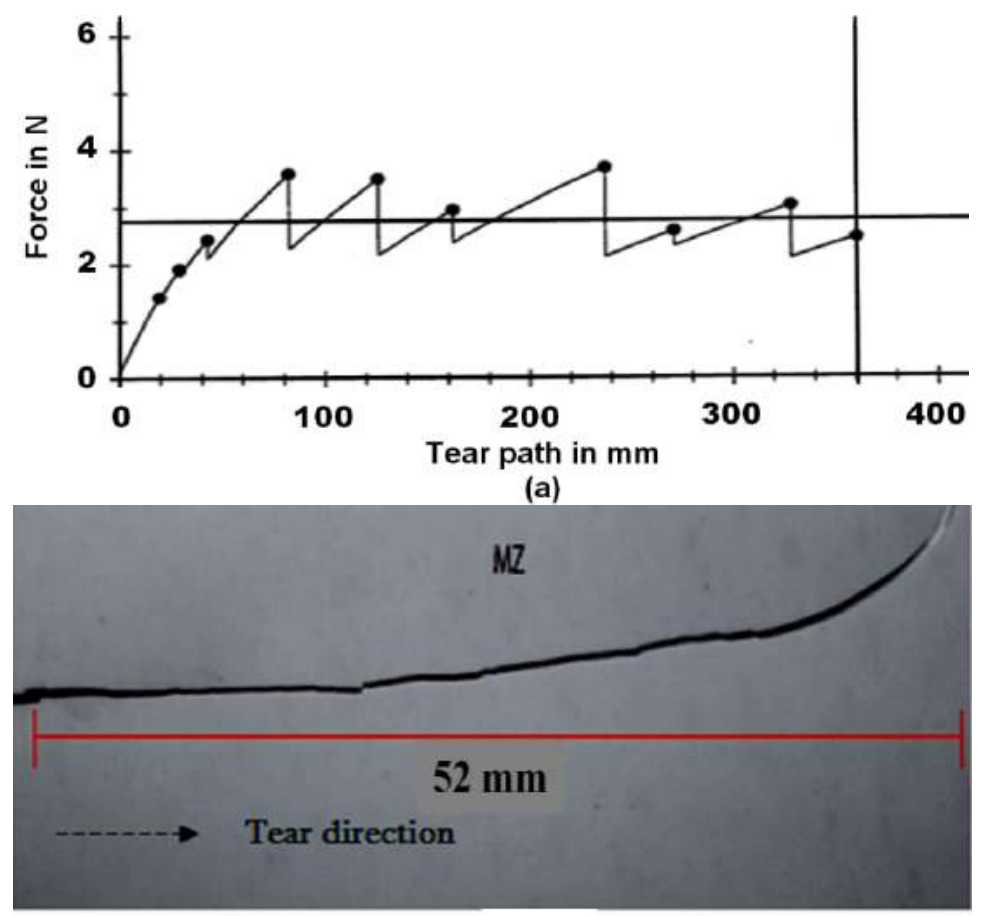

(b)

Figure 7. (a) Tear force vs. tear path diagram and (b) macroscopic tear path of MZ.

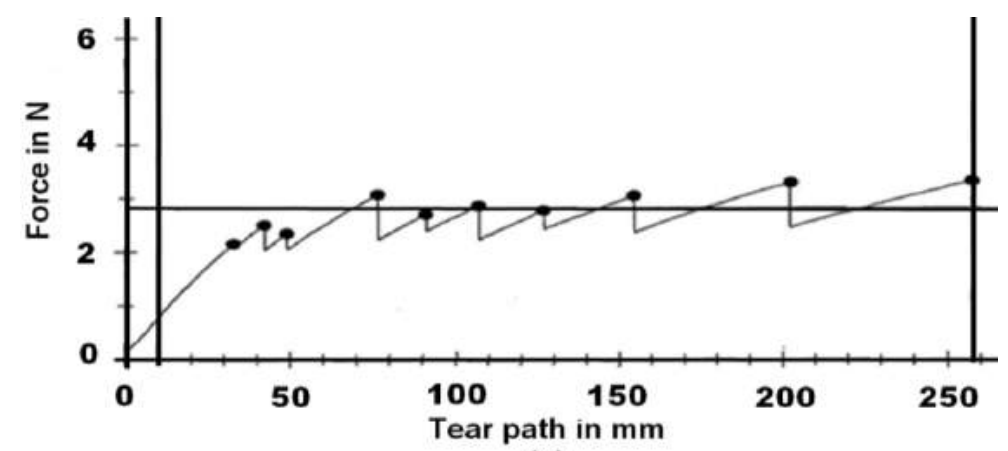

(a)

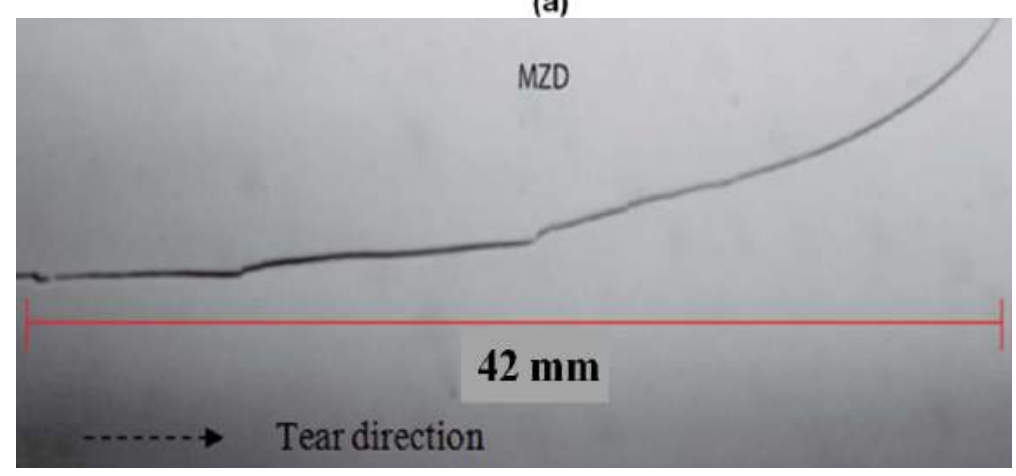

Figure 8. (a) Tear force vs. tear path diagram and (b) macroscopic tear path of MZD. 

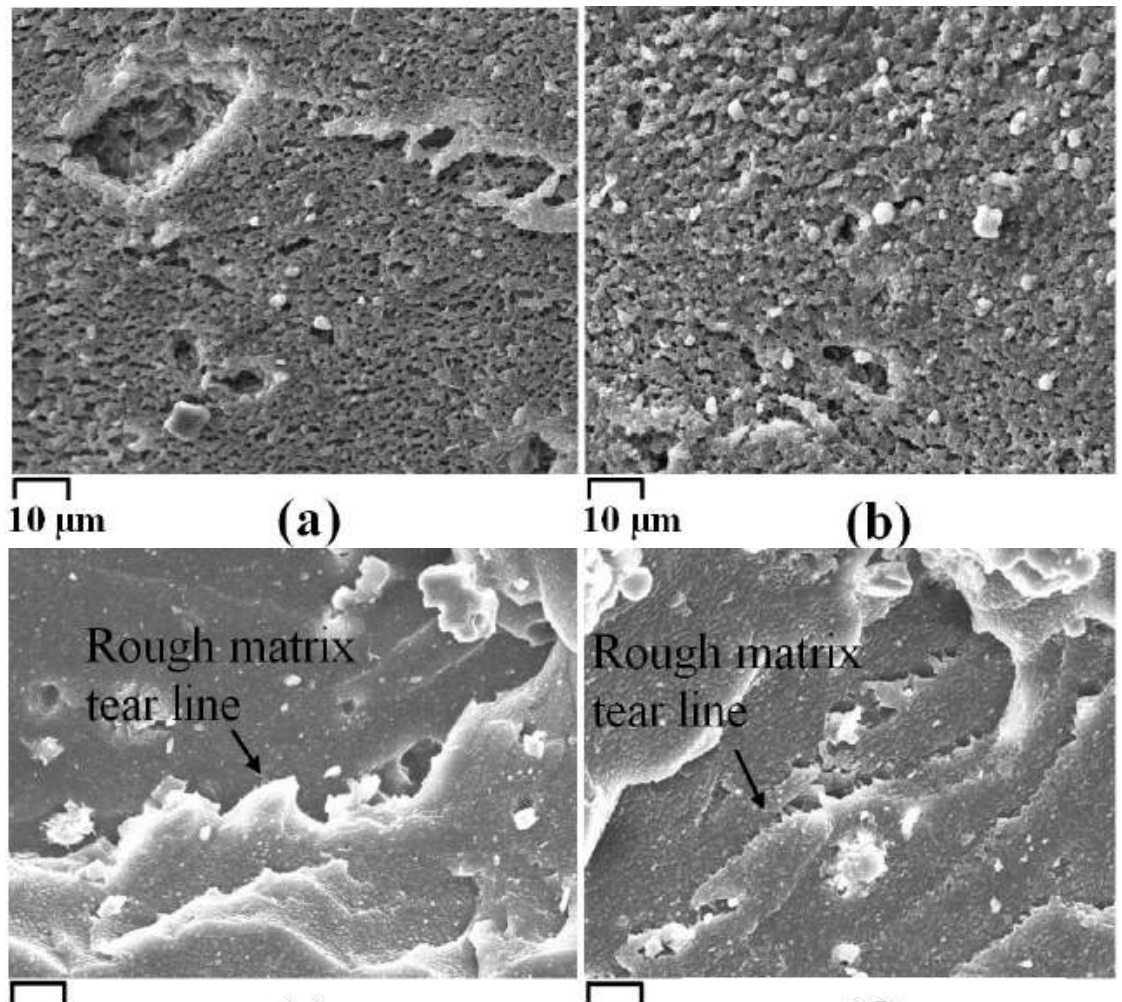

$10 \mu \mathrm{m}$

(b)

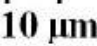

(c)
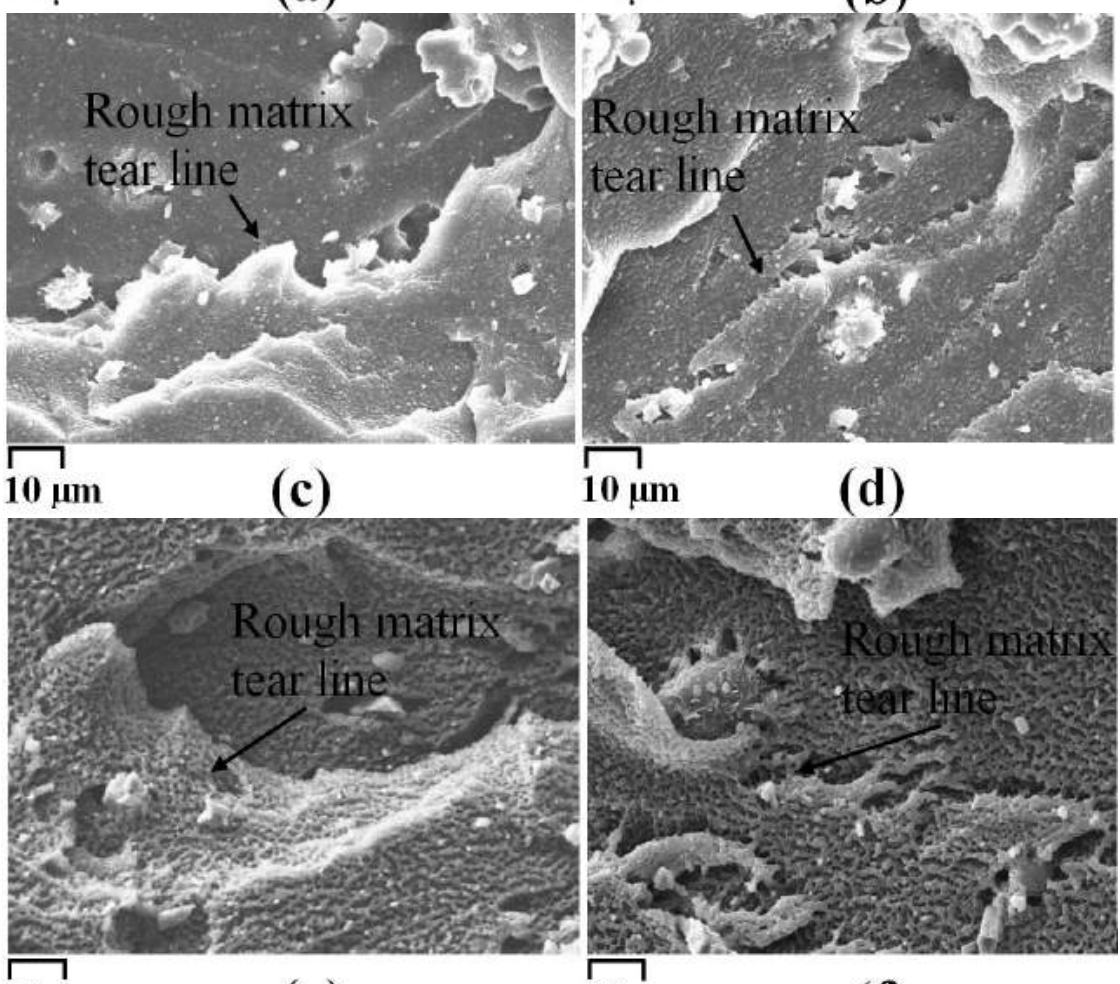

$10 \mu \mathrm{m}$

(d)

$10 \mu \mathrm{m}$

(e)

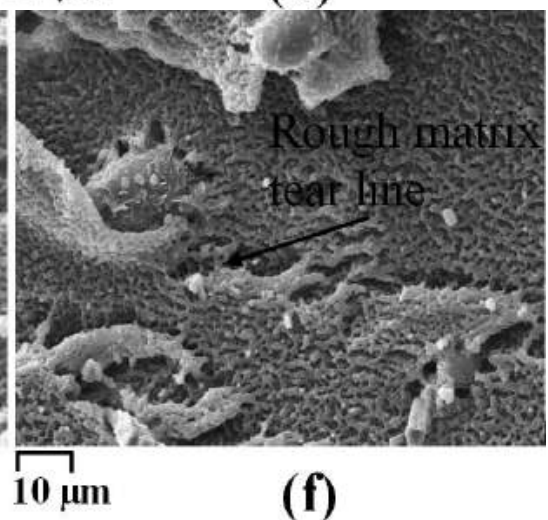

Mag $=1.00 \mathrm{KX} \quad \mathrm{EHT}=15.00 \mathrm{kV}$

Figure 9. SEM secondary electron micrographs of tear surfaces at crack tips (a), (c), (e) and tear path centre (b), (d), (f) of MD, MZ and MZD respectively.

\section{CONCLUSIONS}

The more strongly synergized curing effect of the MD accelerator system imparts better cure activation by initiation of sulphuric crosslinking. It provides the shortest scorch time with the highest cure rate and crosslink density compared with the other accelerator systems (MZ and MZD). Mechanical test results show that MD gives the highest tensile strength and M300\% among the accelerator systems. However, the higher crosslink density obtained with MD contributes to restriction of chains motion. This causes an excessive strain constraint in the rubber matrix, with a detrimental effect on tear strength. 
The results also show that MZD is able to provide improved tear strength with intermediate performance with regard to modulus and tensile strength. They also reveal that the combination of accelerators MBTS/ZMBT/DPG (MZD) provides better scorch safety and tear strength than the conventional MBTS/DPG (MD) accelerator system. The synergism obtained when using these three accelerators has specific advantages for the rubber industry. Future work should focus on the effects of varying the dosages and ratios of these accelerators.

\section{ACKNOWLEDGEMENTS}

The authors would like to acknowledge the Ministry of Higher Education Malaysia for financial support (Program of Engineering Doctorate: KPT(B)740320045317) as well as Universiti Teknikal Malaysia (UTeM) and Rubber Leisure Products Sdn. Bhd. for kind contributions on research materials, test facilities and expertise to carry out this study.

\section{REFERENCES}

[1] Hewitt N, Ciullo P. Compounding precipitated silica in elastomers: theory and practice: William Andrew; 2007.

[2] Khang T, Ariff Z. Vulcanization kinetics study of natural rubber compounds having different formulation variables. Journal of Thermal Analysis and Calorimetry. 2011;109:1545-53.

[3] Choi S-S, Kim E. A novel system for measurement of types and densities of sulfur crosslinks of a filled rubber vulcanizate. Polymer Testing. 2015;42:62-8.

[4] Susamma A, Kurien M, Kuriakose A. New binary accelerator systems for sulphur vulcanisation of styrene butadiene rubber. Plastics, Rubber and Composites. 2004;33:63-70.

[5] Loganathan K. Rubber engineering. Indian Rubber Institute, McGraw-Hill, New York, Chapter. 1998;1.

[6] Bhowmick AK. Rubber products manufacturing technology: CRC Press; 1994.

[7] Gent AN. Engineering with rubber: how to design rubber components: Carl Hanser Verlag GmbH Co KG; 2012.

[8] De SK, White JR. Rubber technologist's handbook: iSmithers Rapra Publishing; 2001.

[9] Aprem AS, Joseph K, Thomas S. Recent developments in crosslinking of elastomers. Rubber Chemistry and Technology. 2005;78:458-88.

[10] Sae-oui P, Sirisinha C, Thepsuwan U, Thapthong P. Influence of accelerator type on properties of NR/EPDM blends. Polymer Testing. 2007;26:1062-7.

[11] FR. E, Mark JE, Erman B, Roland M. The science and technology of rubber: Academic press; 2013.

[12] Prasertsri S, Rattanasom N. Fumed and precipitated silica reinforced natural rubber composites prepared from latex system: mechanical and dynamic properties. Polymer Testing. 2012;31:593-605.

[13] Hassan H, Ateia E, Darwish N, Halim S, El-Aziz AA. Effect of filler concentration on the physico-mechanical properties of super abrasion furnace black and silica loaded styrene butadiene rubber. Materials \& Design. 2012;34:533-40.

[14] Galimberti M. Rubber-clay nanocomposites: science, technology, and applications: John Wiley \& Sons; 2011. 
[15] Ghosh P, Katare S, Patkar P, Caruthers JM, Venkatasubramanian V, Walker KA. Sulfur vulcanization of natural rubber for benzothiazole accelerated formulations: from reaction mechanisms to a rational kinetic model. Rubber Chemistry and Technology. 2003;76:592-693.

[16] Yang S, Liu L, Jia Z, Fu W, Jia D, Luo Y. Study on the structure-properties relationship of natural rubber/SiO 2 composites modified by a novel multifunctional rubber agent. Express Polym Lett. 2014;8:425-35.

[17] Stuart B. Infrared spectroscopy: Wiley Online Library; 2005.

[18] Mohamad N, Zainol NS, Yaakob MY, Abd Razak J. Morphological and mechanical properties of polypropylene/epoxidized natural rubber thermoplastic vulcanizates treated with maleic anhydride-grafted polypropylene. International Journal of Automotive and Mechanical Engineering. 2013;8:1305-15.

[19] Norazlina H, Fahmi A.R.M., Hafizudin. $\mathrm{CaCO} 3$ from seashells as a reinforcing filler for natural rubber. Journal of Mechanical Engineering and Sciences. 2015;8:1481-8.

[20] Umar A, Zainudin E, Sapuan S. Effect of accelerated weathering on tensile properties of kenaf reinforced high-density polyethylene composites. Journal of Mechanical Engineering and Sciences (JMES). 2012;2:198-205.

[21] Cavdar S, Ozdemir T, Usanmaz A. Comparative study on mechanical, thermal, viscoelastic and rheological properties of vulcanised EPDM rubber. Plastics, Rubber and Composites. 2010;39:277-82.

[22] Liu Y, Li L, Wang Q, Zhang X. Fracture properties of natural rubber filled with hybrid carbon black/nanoclay. Journal of Polymer Research. 2011;18:859-67.

[23] Ismail H, Mathialagan M. Comparative study on the effect of partial replacement of silica or calcium carbonate by bentonite on the properties of EPDM composites. Polymer Testing. 2012;31:199-208.

[24] Surya I, Ismail H, Azura A. Alkanolamide as an accelerator, filler-dispersant and a plasticizer in silica-filled natural rubber compounds. Polymer Testing. 2013;32:1313-21. 